\title{
Retratos de um império colonial: Fotografia e colonialismo português em debate
}

\author{
Marcus Vinicius de Oliveira ${ }^{7}$
}

DOI 10.20396/eha.vi14.3390

\section{Introdução}

Em março de 2013, o jornal português Público apresentou uma curta reportagem sobre uma exposição fotográfica que ocorreria no Padrão dos Descobrimentos, em Belém, na capital lusitana. Essa exposição traria o trabalho de fotógrafos comissionados pelo Secretariado da Propaganda Nacional (SPN - órgão responsável pela propaganda do regime salazarista) para documentar a Exposição do Mundo Português de 1940 (a qual teria ocorrido naquela localidade e produzido o monumento que abrigaria o evento ${ }^{2}$. Havia todo um simbolismo de relembrar tal evento naquela localidade, mas também expor ao público interessado os registros fotográficos comprados pela Fundação Calouste Gulbenkian, junto com outras fotografias de instituições que colaboraram para a exposição fotográfica. ${ }^{3}$

A matéria apresentava a existência dos registros fotográficos do certame de 1940 desconhecidos pela população portuguesa como algo surpreendente e revelador de um momento que marcou Lisboa. Essa questão, embora não explicada pela reportagem (pois como essas fotografias permaneceram desconhecidas da população se elas foram encomendadas pelo Estado Novo português através de seu órgão de propaganda?), coloca no horizonte a heterogeneidade dos itinerários da imagem fotográfica, inclusive aquela produzida e encomendada pelo governo salazarista para seus usos de propaganda governamental.

Esse dado é significativo, porque a Exposição do Mundo Português foi um dos grandes eventos públicos organizados pelo regime salazarista. Ela buscava apresentar as glórias de uma nação marítima, colonial e moderna, capaz de organizar uma grande exposição em plena II Guerra Mun-

\footnotetext{
1 Mestre em História Social pela Universidade Federal Fluminense.

2 Embora o original tenha sido desmontado alguns anos após o evento de 1940, o Padrão dos Descobrimentos de Belém foi refeito na década de 1960 e permanece até hoje como um dos pontos turísticos da cidade de Lisboa.

3 Jornal Público de 03 de março de 2013. Disponível em https://www.publico.pt/2013/03/o3/jornal/os-outros-fotografos-do-mundo-portugues-26110553 acessado a 23 de agosto de 2019.
} 
dial e alterar completamente a região de Belém para receber o evento que demonstraria para o mundo as mudanças que o regime salazarista estava produzindo no país e no seu império colonial. Seu investimento em produtos de propaganda foi intenso, já que foram produzidos filmes para serem exibidos ${ }^{4}$ e fotografias para serem publicadas nos veículos de comunicação do regime e em periódicos, sem contar a produção de monumentos históricos instalados em diversos espaços de Lisboa ou mesmo o envio de outros pelas comunidades portuguesas instaladas em outras partes do mundo, como no Brasil (país convidado para participar do evento).

O certame contou também com a presença de várias personalidades e figuras importantes para a construção da mensagem do regime expressa nas Comemorações Centenárias (como também era denominado esse evento público). Intelectuais movimentaram os Congressos do Mundo Português com suas palestras e conferências. Autoridades de Estado estiveram presentes participando da inauguração ou visitando os espaços expositivos, gerando registros e notícias pelos veículos de comunicação, assim como ampliando as alianças do regime com outros governos. Além disso, estiveram presentes membros do governo colonial que ficaram responsáveis por organizar e levar nativos das colônias portuguesas para habitarem o Jardim Colonial ao longo dos seis meses de duração. Portanto, havia também uma relação entre metrópole e mundo colonial que o regime salazarista queria apresentar com o evento de $1940 .^{5}$

Esse certame teve a cobertura de vários fotógrafos, como Horácio Novais (1910-1988), Kurt Pinto (1887-1959), António Passaporte (1901-1983), Álvaro de Azevedo (1896 - 1969), Domingos Alvão (1872-1946), Paulo Guedes, Augusto de Abreu Nunes, Ferreira da Cunha, Eduardo Portugal (1900-1958), Casimiro dos Santos Vinagre (1902-1988) e Mário Novais (1899-1967). Este último possuía acesso exclusivo aos espaços internos das seções históricas e é autor da maioria das fotografias que apresentava a grandeza portuguesa propagandeada pelo SPN nos espaços expositivos, já que o slogan "Portugal não é um país pequeno" atravessava os órgãos de propaganda política nesse período. Essa questão colaborou para a grande difusão das fotografias de Mário Novais nos veículos oficiais do regime, nos cartões fotográficos comercializados, nos álbuns e folhetos referentes ao evento, nas matérias jornalísticas e na própria produção de uma exposição fotográfica com suas imagens, em 1998, no Convento do Beato. Esse circuito intenso ofuscou em partes a produção dos

\footnotetext{
4 O filme O Feitiço do Império de António Lopes Ribeiro estreou em 23 de maio de 1940, no Eden (Lisboa), com presença de chefes de Estado e do governo. Ele ficou em cartaz durante sete semanas, sendo que nesse período ocorreu a inauguração da Exposição do Mundo Português. Cf. MATOS, Patrícia Ferraz. As "côres" do Império: Representações raciais no Império Colonial Português. Lisboa: Imprensa de Ciências Sociais, 2006. 5 Para saber mais sobre a Exposição do Mundo Português e sua seção colonial. Cf. MATOS, Patrícia Ferraz. Op. cit. 2006; e THOMAZ, Omar. Ecos do Atlântico Sul: representações sobre o terceiro império português. Rio de Janeiro: Editora UFR]/Fapesp, 2002.
} 
outros fotógrafos que também registraram o evento de 1940. No entanto, essas fotografias não deixaram de possuir um itinerário social, principalmente no arquivo do SPN, como podemos observar no fundo do órgão de propaganda do Arquivo Nacional Torre do Tombo (TT), em Lisboa.

Porém, se o órgão responsável pela propaganda nacional apenas comissionava o trabalho desses fotógrafos e comprava as imagens para seus arquivos fotográficos, o que os profissionais faziam com os negativos e fotografias que continuavam sob sua responsabilidade em seu estúdio fotográfico? Provavelmente, eles vendiam para outros clientes e desenvolviam outros materiais com as fotografias dos eventos do regime. Tanto que há inúmeras imagens desse certame e de outros organizados nos anos 1930 pelo regime salazarista que ilustraram matérias jornalísticas, souvenires e cartões fotográficos. Logo, podemos sugerir que essas imagens visuais ganharam significados e sentidos para, além daqueles desejados pelo governo salazarista, a ponto de figurarem, hoje, em espólios comprados por instituições, como o Centro Português de Fotografia (CPF) e a Fundação Calouste Gulbenkian (FCC), ou mesmo acervos particulares de alfarrabistas e colecionadores. ${ }^{6}$

Observa-se, deste modo, um circuito social das imagens fotográficas desse evento e de outros organizados pelo regime salazarista extremamente heterogêneo que desloca as problemáticas em torno da visualidade para outros âmbitos que não apenas o seu uso governamental, mas também seus usos artístico, privado e comunicativo (o político se apresenta nessas esferas de outras formas). Algumas imagens foram utilizadas e guardadas dentro dos quadros de propaganda do regime salazarista (como as fotografias de Mário Novaes) e se inscreveram na cultura visual da sociedade portuguesa. ${ }^{7}$ ]á outras fotografias se inscreveram em outros circuitos sociais, onde assumiram usos, funções e significados diversos que podem ser observados hoje, nos arquivos, como: documental (arquivo do Serviço de Propaganda Nacional), artístico (arquivo da Fundação Gulbenkian) e afetivo (coleções privadas). Nesse sentido, é relevante observar nos diferentes itinerários que as fotografias produzidas dentro do projeto colonial português dos anos 1930 e 1940 assumem na atualidade, para compreender a forma como a sociedade portuguesa se relaciona com o seu passado autoritário.

Vale lembrar que esse evento possuía uma seção específica para o mundo colonial (o Jardim Colonial) e muitos desses espólios apresentam registros dos nativos que ficaram expostos durante os seis meses do certame, os quais ganharam certa importância dentro das coleções privadas e

\footnotetext{
6 Em 2018, realizei a pesquisa de arquivo e campo em Portugal para a dissertação de mestrado. A quantidade de fotografias e souvenires de eventos do regime salazarista em alfarrabistas é grande, tanto que comprei na altura alguns postais. Além disso, há um circuito de colecionadores de imagens do colonialismo que também tive contato e pude constatar a quantidade de imagens fotográficas que os Impérios coloniais europeus produziram e ainda perduram ressignificadas no tempo. 7 MITCHELL, W.J.T. What do Pictures Want? The lives and loves of images, Chicago: Chicago University Press, 2005.
} 
documentais atualmente. Não apenas porque a imagem de nativos mobilizava uma série de valores construídos durante o colonialismo, mas também porque, como diversos autores afirmam, o regime salazarista redefiniu as relações de Portugal e seu império colonial a ponto dele não ter condições de existir sem os seus domínios ultramarinos. Logo, a constituição da nacionalidade portuguesa também perpassou no domínio e controle dessas localidades e dos seus habitantes. ${ }^{8}$

Portanto, é importante demarcar que, na configuração dessa linguagem política, a fotografia foi um dos recursos mobilizados para a construção e difusão desse projeto colonial português que emergiu com o Estado Novo. Pois, a imagem fotográfica era o suporte fundamental para criar as hierarquias "civilizacionais" e "raciais" dos territórios coloniais, definir as geografias das localidades que compunham esse Império pluricontinental, instituir práticas e costumes dos seus ocupantes como naturais e, principalmente, promover uma forma de pensar e agir o colonialismo a partir de imagens visuais. Já que, estas educavam uma população, majoritariamente, analfabeta para os desígnios de um colonialismo em construção que, todavia, se afirmava como histórico, tradicional e constituinte da própria essência portuguesa. ${ }^{9}$ Em face da centralidade da prática fotográfica na propaganda política salazarista em seu período de consolidação (anos 1930 e 1940), indaga-se sobre o apagamento desses registros na memória pública, sobretudo, através da sua ressignificação como objeto artístico na atualidade.

A sua existência para além do período de produção aponta para questões importantes, como a permanência dos efeitos do projeto colonial na sociedade portuguesa, já que o colecionismo de "tipos exóticos" e da grandeza de Portugal que essas imagens propagavam ganharam outros significados e status, principalmente aquele que o qualifica como objetos artísticos. Sua dimensão política foi reconfigurada para outras demandas e esteve relacionada às mudanças que a sociedade portuguesa passou durante o século XX. Afinal, a utilização dessas imagens visuais em exposições fotográficas e publicações definiram outros valores de consumo para esses objetos materiais..$^{10} \mathrm{Ou}$ mesmo a procura por imagens fotográficas desse período por portugueses que cresceram no pós-25 de abril de $1974^{11}$ e não viveram o colonialismo (mas que, no entanto, se formaram em uma socieda-

\footnotetext{
8 Vários autores portugueses pontuam as relações intrínsecas entre o Estado Novo Português e seu domínio colonial como parte fundamental da manutenção do regime. Cf. ALEXANDRE, Valentim. Velho Brasil, Novas Áfricas: Portugal e o Império 1808-1975. Porto: Afrontamento, 2000; ROSAS, Fernando. O Estado Novo (1926-1974). MATTOSO, José (Dir.). História de Portugal, VII Volume. Lisboa: Editorial Estampa, 1994.

9 OLIVEIRA, Marcus V. À sombra do colonialismo: Fotografia, circulação e projeto colonial (1930-1951). Niterói: Universidade Federal Fluminense (dissertação de mestrado), 2019.

10 Há uma série de produtos culturais criados com fotografia nesse período, inclusive ilustração de livros que não necessariamente foram produzidos pelo governo salazarista, embora também não deixassem de favorecer a construção do projeto colonial nos anos de consolidação do Estado Novo.

11 No dia 25 de Abril de 1974, em Portugal, ocorreu uma revolução que desmantelou o Estado Novo Português. Para Raquel Varela, a rev-
} 
de que possui algumas dificuldades para lidar com sua memória colonial nacional) também indica para essas alterações dos usos políticos ao longo do curso da história portuguesa no século XX.

Nestes termos, coloca-se em perspectiva como o colonialismo impactou os circuitos sociais da fotografia nessa sociedade, conferindo espaços de exposição e consumo de acordo com as demandas e objetivos dos agenciadores da imagem fotográfica, os quais não deixaram de corresponder a resquício das permanências da experiência colonial em Portugal. Além disso, sinaliza-se também de que forma essas imagens visuais provocaram a construção e reprodução de uma memória colonial portuguesa. Logo, esses apontamentos ampliam a análise dos usos e funções da fotografia dentro de uma propaganda política moderna realizada pelo colonialismo contemporâneo, assim como, reforçam a proposta de fotografia pública de Ana Mauad.

Para a autora, existem fatos, situações e vivências que só podem ser conhecidos porque eles foram fotografados, deste modo, a experiência fotográfica define-se como uma experiência histórica. $^{12}$ Logo, a imagem fotográfica se torna a própria questão da pesquisa histórica, indicando os problemas em torno das visualidades em disputa na história contemporânea. Portanto, torna-se necessário realizar um esforço para pensar a centralidade da fotografia na história do colonialismo português. Colocando em evidência que a produção fotográfica em contextos coloniais foi muito mais complexa que sua mera utilização para a propaganda governamental, já que dentro de um espectro de consumo pelo público uma série de valores, sentidos e normas podiam estar presentes. Além disso, reconhecer que a fotografia foi mobilizada para construir a própria experiência colonial na metrópole lusitana e, desse modo, possui diversos elementos para pensar esse período histórico através dela. Assim, enquanto um documento histórico dotado de relações sociais, a sua investigação histórica se torna ainda mais necessária, já que permite dimensionar qual seria o papel desempenhado pelas imagens fotográficas no colonialismo português contemporâneo e quais são os seus impactos na construção da própria memória nacional desse país.

olução começou nas lutas anticoloniais e no próprio impacto dos 13 anos de guerra colonial que envolveu a sociedade portuguesa. Logo, reforça também as conexões entre o mundo metropolitano e colonial na construção e destruição da ditadura portuguesa. VARELA, Raquel. "O povo já não tem medo": 025 de Abril de 1974 em Portugal - das revoluções anticoloniais à revolução na metrópole. In: MATTOS, Marcelo; VECA, Rubén. Trabalhadores e Ditaduras: Brasil, Espanha e Portugal. Rio de Janeiro: Consequência, 2014, pp. 99-124. 


\section{Referências bibliográficas}

ALEXANDRE, Valentim. Velho Brasil, Novas Áfricas: Portugal e o Império 1808-1975. Porto: Afrontamento, 2000. APPADURAI, Arjum. A Vida Social das Coisas: As Mercadorias sob uma Perspectiva Cultural. Niterói: Eduff, 2009. EDWARDS, Elizabeth and HART, Janice (ed.). Photographs Objects Histories: On the materiality of images, London/ New York: Routledge, 2004.

JERÓNIMO, Miguel Bandeira (Org.). $O$ império colonial em questão (Sec. XIX-XX): Poderes, saberes e instituições. Lisboa: Edições 70, 2013.

MATOS, Patrícia. As "côres" do Império: Representações raciais no Império Colonial Português. Lisboa: Imprensa de Ciências Sociais, 2006

MAUAD, Ana Maria. Fotografia pública e cultura do visual, em perspectiva histórica. IN: Revista Brasileira de História da Mídia. Vol. 2, n², jul. 2013/dez. 2013.

Sobre as imagens na História, um ba lanço de conceitos e perspectivas. In: Revista Maracanan, publicação dos docentes do PPGH-UER], vol. 12, n.14, 2016. p. 33-48.

MIRZOEFF, Nicholas. An Introduction to Visual Culture, London/New York: Routledge, 2003.

MITCHELL, W.J.T. What do Pictures Want? The lives and loves of images, Chicago: Chicago University Press, 2005.

OLIVEIRA, Marcus V. À sombra do colonialismo: Fotografia, circulação e projeto colonial. Niterói: Universidade Federal Fluminense (dissertação de mestrado), 2019.

ROSAS, Fernando. O Estado Novo (1926-1974). MATTOSO, José (Dir.). História de Portugal, VII Volume. Lisboa: Editorial Estampa, 1994.

SENA, António. História da imagem fotográfica em Portugal (1839-1997). Porto: Porto Editora, 1998.

STOLLER, Ann. Colonial Archives and the Arts of Governance. In: Archival Science 2, 2002. p. 87-109

TACC, John. The Burden of representation: essays on photographies and histories. Mineapolis: University of Minesota Press, 1988

THOMAZ, Omar. Ecos do Atlântico Sul: representações sobre o terceiro império português. Rio de Janeiro: Editora UFRJ/Fapesp, 2002.

VICENTE, Filipa Lowndes (Org.). 0 império da visão: fotografia no contexto colonial português (1860-1960). Lisboa: Edições 70, 2014. 